\title{
PALEOBIOLOGY OF EARLY ANGIOSPERMS: EVIDENCE FROM SEDIMENTOLOGICAL ASSOCIATIONS IN THE EARLY CRETACEOUS POTOMAC GROUP OF THE EASTERN U.S.A.
}

HICKEY*, Leo J., Dept. of Geology and Geophysics, Yale University, 170 Whitney Ave., P.O. Box 6666, New Haven, CT 06520, U. S. A.; TAYLOR, David W., Dept. of Biology, Indiana University Southeast, 4201 Grant Line Rd., New Albany, IN 47105, U. S. A.

Lately, we proposed a hypothesis that the ancestral angiosperm was a diminutive, rhizomatous to scrambling perennial herb with small simple flowers. Our phylogenetic studies suggest that arborescent to shrubby magnolialians with large, multiparted, complex flowers are derived, rather ancestral as commonly thought. We suggest that the early angiosperm, due to its rhizomatous habit, would have been able to survive in more ephemeral habitats. A test of this idea would be to examine the sedimentological context of early angiosperms.

Despite a number of reports of early angiosperm megafossils from Barremian to middle Albian (mid- to late Early Cretaceous) age sediments, only the Potomac Group of the eastern U.S.A. has provided a stratigraphic sequence of early angiosperm diversification.

Furthermore, study of this sequence has also linked observations on floristic assemblages to the lithofacies in which they occur, leading Doyle and Hickey to report an ecological expansion of early angiosperms from relatively near-channel environments to a much broader range of flood plain sites during the Barremian/Aptin to latest Albian/early Cenomanian interval represented by Potomac Group deposition. From this those authors inferred that the early angiosperms were "riparian weeds" that grew on moderately unstable, near-channel sites subject to periodic flooding and episodes of alluviation.

We recently expanded on these inferences by examining the sedimentology of Dutch Gap, an early angiosperm site at the earliest level of the Potomac Group (Barremain/Aptian-Pollen Zone I) near Richmond, VA. Sediments here appear to represent the meander belt of a fluvial setting. A series of multi-storied channel units at the site are filled with arkosic, medium to coarse, sub-angular sand with pebble- to boulder-size clasts of gneiss, claystone and mudstone concentrated at channel bases, reactivation surfaces, and on lateral accretion surfaces. These channels are cut into inferred levee and splay deposits that consist of thin interbeds of sand and silt alternating with dark grey, micaceous mudstone to claystone. This sequence fines in an inferred distal direction from the channels and the mudstone/claystone interbeds thicken at the expense of the coarser units until they coalesce into relatively thick, dark grey clay beds with only thin silty laminae. These beds are thought to represent floodbasin deposits.

The megafossil plants recovered from our studies at Dutch Gap exhibit a clear pattern of association with each other and with these lithofacies. Angiosperms (Celastrophyllum, Rogersia, and an unnamed new form) together with ferns are found in relatively silty interbeds that lie in what appear to be distal levee settings, while the backswamp was dominated by the bennittitalean Dioonites buchianus. Conifers of diverse kinds are dominant only in pinkish, silty clay clasts that are inferred to have been transported from drier flood-plain environments.

This study provides added evidence of an association between early angiosperms and moderately unstable, channel-margin sites and, in addition, calls attention to the potential that detailed sedimentological investigations have of providing important evidence on early angiosperm paleoecology. 